\title{
Schmerz zwischen Natur und Kultur
}

Erhard Taverna

1 Schönbächler G (Hrsg.). Schmerz. Zürich: Chronos; 2007. 258 Seiten mit Illustrationen von Regula Vollenweider.
Eines ihrer bekanntesten Selbstbildnisse nannte Frida Kahlo (1907-1954) «Die zerbrochene Säule». Tränen laufen ihr über das Gesicht, und zahlreiche Nägel verletzen die Haut. Im längs aufgerissenen Halbakt, dessen Körperteile Metallbänder zusammenhalten, steckt eine mehrfach zerbrochene Säule. Die Künstlerin wurde bei einem Busunfall 1925 schwer verletzt, war danach monatelang eingegipst und wurde in den folgenden Jahrzehnten über 30mal an der Wirbelsäule und am Fuss operiert. In ihrem gemalten Tagebuch finden sich zwei amputierte Füsse auf einem Sockel mit der Inschrift: «Pies para qué los quiero si tengo alas pa'volar» - Wozu brauche ich Füsse, wenn ich Flügel zum Fliegen habe. Die ikonographischen Traditionen und visuellen Kontinuitäten thematisiert Jakob Tanner. «Kann sie», nach der kreativen Kraft im Schmerz, «für kulturelle Leistungen nutzbar gemacht werden?» fragt Georg Schönbächler, Herausgeber und Mitautor, im letzten Kapitel einer Vortragsreihe des Collegium Helveticum von 2005/06 zum Thema «Schmerz - Perspektiven auf eine menschliche Grunderfahrung» [1].

17 Autorinnen und Autoren versuchen eine Annäherung an den Schmerz, biologisch, kulturell und historisch, therapeutisch und philosophisch, Forscher, Kliniker und Schriftsteller. Aus den gesammelten Texten ist, mit den Illustrationen der Ärztin Regula Vollenweider, ein informatives und handwerklich sehr schönes Buch geworden. Zwar ist der Schmerz ein Wortvernichter, doch wer bemüht ist, seine Wirkung zu lindern, darf und soll sich mitteilen, wie es hier geschieht. Sehr viel Wissen und Erfahrung im Umgang mit Patienten wurde im Winter- und Sommersemester öffentlich gemacht: Aspekte der Physiologie und Therapie, interdisziplinäre Behandlungen, Kulturgeschichte, Reden vom eigenen Schmerz, Wege der Chronifizierung, Fallstudien, Krankengeschichten, Köperschemastörungen und, am Beispiel des Ätherrausches, eine Geschichte von Lust und Schmerz. Die Referate ergänzen sich, und jedes lohnt gleichermassen die Lektüre. Wenn einige in dieser Rezension namentlich erwähnt werden, dann immer als Teil eines ausgewogenen Ganzen. Die Sinnfrage der Schmerzerfahrung steht wiederholt im Mittelpunkt. Sind Schmerzen immer nur

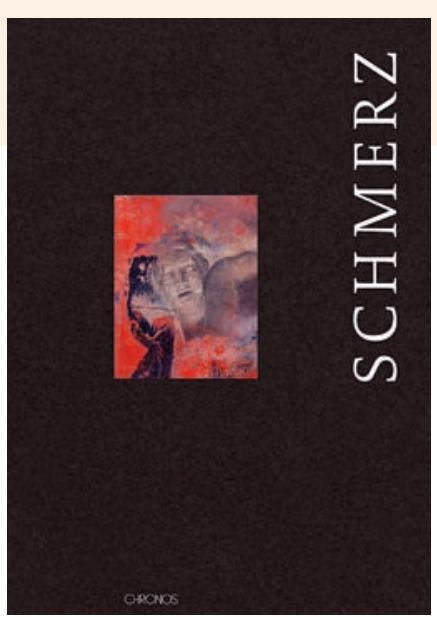

schlecht, haben sie einen Wert, kann man sogar von einem Recht auf diese sprechen? «[...] ein Leben ohne Schmerzen zu führen, so wünschenswert es auch sein mag, sollte kein zentrales Projekt sein», so Peter Schaber, Professor für Ethik an der Universität Zürich. Provokativ und originell hat Adolf Muschg unter dem Titel «Recht auf Schmerz» zum Thema beigetragen. Er geht von der Schmerzklinik aus, die er als Konzession der Medizin «an das unansehnliche Segment ihres Krankengutes» betrachtet. Genauer geht es ihm um die Akzeptanz der Äusserung von Schmerzen, als von einem rohen und nackten Phänomen, «das unterhalb des Diskutablen, sogar ausserhalb der Sprache liegt - denn was so wenig zu messen ist, lässt sich für andere nicht ermessen». Wissen wir, woran wir leiden, besteht auch Aussicht auf Behandlung, denn Schmerz ist nur als erzählter Schmerz erkennbar. Für Muschg ist klar: «Wir haben Kunst nötig, um die Natur, in jedem Sinn, auch die Natur unseres Körpers, zu ertragen.» Das Sterben und Aushalten von Schmerzen kennt viele Kunstwerke: den Freitod der Stoiker, das gelungene Harakiri des Samurai oder den Schmerzensmann am Kreuz. Vom Schmerz mit Gelassenheit zu reden vermögen die attischen Grabstelen im Berliner Pergamonmuseum: «Diese Trauer ist schön; davon wird sie nicht weniger.» Dem Betrachter bleiben sie Hoffnung und Vorbild. «Schmerz zwischen Natur und Kultur» hätte als übergreifender Titel auch zur Veranstaltung gepasst, denn die naturwissenschaftlichen Untersuchungen sind das eine und die kulturellen Praktiken der Wahrnehmung und Kontrolle das andere. Für jeden Bereich finden Leser und Leserinnen eine Fülle von Fakten und Anregungen, die das Lesen belohnen. 